\title{
Genotypic Variation in Nickel Accumulation and Translocation and Its Relationships with Silicon, Phosphorus, Iron, and Manganese among 72 Major Rice Cultivars from Jiangsu Province, China
}

\author{
Ya Wang ${ }^{1,2} \mathbb{1}$, Chengqiao Shi ${ }^{1,2}$, Kang $\mathrm{Lv}^{1,2}$, Youqing $\mathrm{Li}^{1,2}$, Jinjin Cheng ${ }^{1,2}$, Xiaolong Chen ${ }^{1,2}$, \\ Xianwen Fang ${ }^{3}$ and Xiangyang $\mathrm{Yu}^{1,2, *}$ \\ 1 Jiangsu Key Laboratory for Food Quality and Safety-State Key Laboratory Cultivation Base, Ministry of \\ Science and Technology, Nanjing 210014, China \\ 2 Institute of Food Safety and Nutrition, Jiangsu Academy of Agricultural Sciences, Nanjing 210014, China \\ 3 National Crop Germplasm Resources Infrastructure (Jiangsu), Ministry of Science and Technology, \\ Nanjing 210014, China \\ * Correspondence: yuxy@jaas.ac.cn
}

Received: 13 August 2019; Accepted: 3 September 2019; Published: 6 September 2019

\begin{abstract}
Nickel (Ni) is a ubiquitous environmental toxicant and carcinogen, and rice is a major dietary source of $\mathrm{Ni}$ for the Chinese population. Recently, strategies to decrease $\mathrm{Ni}$ accumulation in rice have received considerable attention. This study investigated the variation in $\mathrm{Ni}$ accumulation and translocation, and also multi-element (silicon $(\mathrm{Si})$, phosphorus $(\mathrm{P})$, iron $(\mathrm{Fe})$, and manganese $(\mathrm{Mn}))$ uptake and transport among 72 rice cultivars from Jiangsu Province, China, that were grown under hydroponic conditions. Our results showed a 2.2-, 4.2-, and 5.3-fold variation in shoot $\mathrm{Ni}$ concentrations, root Ni concentrations, and translocation factors (TFs) among cultivars, respectively. This suggests that $\mathrm{Ni}$ accumulation and translocation are significantly influenced by the genotypes of the different rice cultivars. Redundancy analysis of the 72 cultivars revealed that the uptake and transport of Ni were more similar to those of $\mathrm{Si}$ and Fe than to those of $\mathrm{P}$ and $\mathrm{Mn}$. The Ni TFs of high-Ni cultivars were significantly greater than those of low-Ni cultivars $(p<0.001)$. However, there were no significant differences in root $\mathrm{Ni}$ concentrations of low-Ni and high-Ni cultivars, suggesting that high-Ni cultivars could translocate $\mathrm{Ni}$ to shoots more effectively than low-Ni cultivars. In addition, the cultivars HD8 and YD8 exhibited significantly lower levels of Ni accumulation than their parents $(p<0.05)$. Our results suggest that breeding can be an effective strategy for mitigating excessive $\mathrm{Ni}$ accumulation in rice grown in $\mathrm{Ni}$-contaminated environments.
\end{abstract}

Keywords: Oryza sativa L.; toxic element; redundancy analysis; cultivar variation

\section{Introduction}

Nickel (Ni) is a ubiquitous trace metal that has both natural and anthropogenic sources (e.g., vehicle emissions, as well as the Ni mining, smelting, cement manufacture, metallurgical, and electroplating industries), and its environmental accumulation has become a concern worldwide [1,2]. In recent years, fertilizer and organic manure use have increased $\mathrm{Ni}$ concentrations in cropland soils, exacerbating the problem of Ni pollution [2,3]. A recent nationwide Chinese soil survey revealed that $19.4 \%$ of the cropland soil samples were polluted. Ni was the second most abundant (4.8\%) potentially toxic element (PTE) in soil and a key pollutant of Chinese farmlands [4]. In Jiangsu Province, located in the eastern coastal region of China, the surface soil $(0-20 \mathrm{~cm})$ background concentrations of Ni varied from 1.6 to $238 \mathrm{mg} \cdot \mathrm{kg}^{-1}$, with a geometric mean of $32.9 \mathrm{mg} \cdot \mathrm{kg}^{-1}$ [5]. Although the average soil Ni concentration 
in Jiangsu is below the $40 \mathrm{mg} \cdot \mathrm{kg}^{-1}$ class II standard described by the environmental quality standard for soils of China (GB 15618-1995), the level of Ni pollution cannot be ignored, especially in southern Jiangsu where the level of anthropogenic contamination has increased [5,6]. In fact, a geological survey found that among all soils polluted with PTEs in Jiangsu Province, Ni-polluted soils were the most common (2.91\% of all agricultural soils tested) [5]. The recent increase in the levels of Ni soil pollution and its implications for adverse effects on human health have focused attention on the processes of $\mathrm{Ni}$ accumulation and translocation in cereal crops [3,7-9].

Rice (Oryza sativa L.) is a staple food for approximately half of the global population $[10,11]$. However, rice grains also accumulate PTEs (e.g., cadmium (Cd), arsenic (As), and Ni) efficiently [8,12-14]. In contrast to PTEs such as $\mathrm{Cd}$ and As, $\mathrm{Ni}$ is an essential micronutrient that is required for plant growth because it is a key component of the enzyme urease $[3,7,15]$. However, at high levels, $\mathrm{Ni}$ is toxic to rice and can inhibit seed germination [16], suppress growth and reduce biomass [7], decrease the quantity of photosynthetic pigments [7], stimulate lipid peroxidation [15], and disrupt carbohydrate metabolism [17]. Although Ni is essential for plant growth, it has no proven biochemical function in humans and may be unnecessary $[8,9]$. Furthermore, the presence of Ni may increase the likelihood of cancer, heart attacks, skin problems, vomiting, and respiratory illnesses $[8,9,18]$. Consequently, the European Union has implemented a maximum permitted level of $75 \mu \mathrm{g} \mathrm{Ni}$ day $^{-1}$ in the diet [19]. However, Ni is one of the most abundant PTEs found in rice [9,13], and its geometric mean varies from 0.46 to $0.54 \mathrm{mg} \cdot \mathrm{kg}^{-1}$ in the three main rice-producing regions of China [20]. This is a much higher Ni concentration than is typical of rice from other countries [13,21]. Consequently, rice is a major dietary source of $\mathrm{Ni}$ for the Chinese population, especially individuals who consume a lot of rice.

Food safety strategies to reduce $\mathrm{Ni}$ assimilation into rice are considered important but have received less attention than those focusing on other PTEs such as lead $(\mathrm{Pb})$, mercury $(\mathrm{Hg}), \mathrm{As}, \mathrm{Cd}$, and chromium $(\mathrm{Cr})[9-12,14]$. Phytoremediation and soil flushing techniques are promising methods for the remediation of PTE-contaminated soils [22]. However, serious limitations such as low biomass, propagation difficulties, and the time and expense involved have prevented these methods from being used on a wider scale [2,22]. Recent research has demonstrated that inter-cultivar variation plays a significant role in determining PTE concentrations in rice grains $[23,24]$. Therefore, selecting cultivars that restrict $\mathrm{Ni}$ translocation and accumulation in rice grains may be the simplest cost-effective approach to preventing excessive $\mathrm{Ni}$ accumulation. Interestingly, nutrient elements such as silicon $(\mathrm{Si})$ and phosphorus $(\mathrm{P})$ can affect the growth and yield of rice $[25,26]$. Furthermore, they can influence the uptake of PTEs, such as Cd and As [27-33]. However, it is unclear whether Ni translocation and accumulation can be influenced by $\mathrm{Si}$ and $\mathrm{P}$ in different rice subgroups. In addition, many studies have demonstrated that iron $(\mathrm{Fe})$ and manganese $(\mathrm{Mn})$ play important roles in mediating the accumulation of PTEs (e.g., As, $\mathrm{Cd}, \mathrm{Pb}$, and $\mathrm{Ni}$ ) in rice through the formation of plaque deposits on the roots [33-39]. Nevertheless, the relationships between the uptake and translocation of $\mathrm{Ni}$ and other elements may differ among rice genotypes, and further studies are needed to understand these relationships.

In this study, we performed short-term Ni uptake experiments with 72 major rice cultivars that were grown under hydroponic conditions. The objectives of the study were to (1) evaluate the variation in $\mathrm{Ni}$ accumulation and translocation among 72 rice cultivars, (2) analyze the relationships among $\mathrm{Ni}$ and multi-element (Si, $\mathrm{P}, \mathrm{Fe}$, and $\mathrm{Mn}$ ) uptake and translocation among the rice cultivars, and (3) identify the major factors that affect the accumulation and translocation of $\mathrm{Ni}$ in different rice genotypes.

\section{Materials and Methods}

\subsection{Rice Cultivars and Growth Conditions}

Table 1 lists the 72 major rice (O. sativa L.) cultivars used in this study, including 64 japonica cultivars and 8 indica cultivars (YD1-8). These cultivars were obtained from the national crop germplasm resources infrastructure (Jiangsu, China), the Ministry of science and technology (Beijing, China), 
and the Jiangsu academy of agricultural sciences (Nanjing, China). Rice seeds were surface-sterilized in $30 \%$ (v/v) hydrogen peroxide for $15 \mathrm{~min}$, washed three times in sterile deionized water [40], and then transferred to an incubator for germination in the dark at $32{ }^{\circ} \mathrm{C}$ for 2 days. Pre-germinated rice seedlings were grown hydroponically in a nutrient solution, in accordance with the method described by the international rice research institute under the following conditions: $12 \mathrm{~h}$ light/12 $\mathrm{h}$ dark cycle (light fluence rate, $360 \mu \mathrm{mol} \mathrm{m} \mathrm{m}^{-2} \cdot \mathrm{s}^{-1}$ ) at $30{ }^{\circ} \mathrm{C} / 25{ }^{\circ} \mathrm{C}$ in an environmental chamber with a relative humidity of $60-70 \%$ [41]. The seedlings were cultured in sterile deionized water before the one-leaf stage, and in 0.25- and 0.5-strength nutrient solutions at the two- and three-leaf stages, respectively. The nutrient solutions were renewed every 3 days, and the $\mathrm{pH}$ of the solutions was maintained at 5.6 with $5 \mathrm{mmol} \cdot \mathrm{L}^{-1} 2$-(N-morpholino) ethanesulfonic acid [41,42].

Table 1. Rice cultivars from Jiangsu Province.

\begin{tabular}{|c|c|c|c|c|c|}
\hline Number & Name & Abbreviation & Number & Name & Abbreviation \\
\hline 1 & Huaidao 5 & HD5 & 37 & Wujing 13 & WJ13 \\
\hline 2 & Huaidao 6 & HD6 & 38 & Wujing 15 & WJ15 \\
\hline 3 & Huaidao 7 & HD7 & 39 & Wuyujing 3 & WYJ3 \\
\hline 4 & Huaidao 8 & HD8 & 40 & Wuyunjing 7 & WYJ7 \\
\hline 5 & Huaidao 9 & HD9 & 41 & Wuyunjing 11 & WYJ11 \\
\hline 6 & Huaidao 10 & HD10 & 42 & Wuyunjing 19 & WYJ19 \\
\hline 7 & Huaidao 11 & HD11 & 43 & Wuyunjing 24 & WYJ24 \\
\hline 8 & Huaidao 12 & HD12 & 44 & Wuxiangjing 14 & WXJ14 \\
\hline 9 & Huaidao 13 & HD13 & 45 & Xudao 4 & XD4 \\
\hline 10 & Lianjing 06-3 & LJ06-3 & 46 & Xudao 5 & XD5 \\
\hline 11 & Lianjing 3 & LJ3 & 47 & Xudao 7 & XD7 \\
\hline 12 & Lianjing 4 & LJ4 & 48 & Yangdao 1 & YD1 \\
\hline 13 & Lianjing 5 & LJ5 & 49 & Yangdao 2 & YD2 \\
\hline 14 & Lianjing 6 & LJ6 & 50 & Yangdao 3 & YD3 \\
\hline 15 & Lianjing 6 (early rice) & LJ6 (early rice) & 51 & Yangdao 4 & YD4 \\
\hline 16 & Lianjing 7 & LJ7 & 52 & Yangdao 5 & YD5 \\
\hline 17 & Lianjing 8410 & LJ8410 & 53 & Yangdao 6 & YD6 \\
\hline 18 & Lianjing (new) & LJ (new) & 54 & Yangdao 7 & YD7 \\
\hline 19 & Nanjing 11 & NJ11 & 55 & Yangdao 8 & YD8 \\
\hline 20 & Nanjing 15 & NJ15 & 56 & Yangjing 203 & YangJ203 \\
\hline 21 & Nanjing 23 & NJ23 & 57 & Yangjing 4022 & YangJ4022 \\
\hline 22 & Nanjing 26 & NJ26 & 58 & Yangjing 4227 & YangJ4227 \\
\hline 23 & Nanjing 29 & NJ29 & 59 & Yanjing 2 & YJ2 \\
\hline 24 & Nanjing 34 & NJ34 & 60 & Yanjing 8 & YJ8 \\
\hline 25 & Nanjing 35 & NJ35 & 61 & Yanjing 9 & YJ9 \\
\hline 26 & Nanjing 37 & NJ37 & 62 & Yanjing 11 & YJ11 \\
\hline 27 & Nanjing 39 & NJ39 & 63 & Yanjing 48 & YJ48 \\
\hline 28 & Nanjing 46 & NJ46 & 64 & Yanjing 456 & YJ456 \\
\hline 29 & Nanjing 47 & NJ47 & 65 & Yanjing 6241 & YJ6241 \\
\hline 30 & Nanjing 5055 & NJ5055 & 66 & Yanjing 6243 & YJ6243 \\
\hline 31 & Sujing 2 & SJ2 & 67 & Zhendao 4 & ZD4 \\
\hline 32 & Sujing 4 & SJ4 & 68 & Zhendao 10 & ZD10 \\
\hline 33 & Sujing 5 & SJ5 & 69 & Zhendao 16 & ZD16 \\
\hline 34 & Tongjing 3 & TJ3 & 70 & Zhendao 42 & ZD42 \\
\hline 35 & Tongjing 4 & TJ4 & 71 & Zhendao 88 & ZD88 \\
\hline 36 & Tongjing 981 & TJ981 & 72 & Zhendao 99 & ZD99 \\
\hline
\end{tabular}

\subsection{Experimental Design}

Uniform 20-day-old rice seedlings at the three-leaf stage were selected and cultured in 400-mL plastic cups. Each cup contained three seedlings and $350 \mathrm{~mL}$ of 0.5 -strength nutrient solution. The seedlings were treated with 0 and $10 \mu \mathrm{mol} \cdot \mathrm{L}^{-1} \mathrm{Ni}$ [7], and each treatment was replicated three times. A Ni stock solution was prepared from nickel sulfate hexahydrate $\left(\mathrm{NiSO}_{4} \cdot 6 \mathrm{H}_{2} \mathrm{O}\right)$. After exposure 
to $10 \mu \mathrm{mol} \cdot \mathrm{L}^{-1} \mathrm{Ni}$ for 3 days (short-term experiment), the rice samples were collected, rinsed three times with deionized water, and then separated into shoots and roots. In addition, $2 \mathrm{~mL}$ aliquots of the nutrient solution from each replicate were filtered using a $0.45-\mu \mathrm{m}$ syringe filter and then stored at $4{ }^{\circ} \mathrm{C}$ to determine the total $\mathrm{Ni}$ concentrations. After oven-drying the sample tissues for 2 days at $60{ }^{\circ} \mathrm{C}$, the dry weights of the shoots and roots were recorded. Then, the tissues were ground using zirconia beads in a high-throughput sample grinder (CK-2000; Thmorgan, Beijing, China). The translocation factor (TF) was calculated as the shoot Ni concentration/root Ni concentration. The bioconcentration factor $(\mathrm{BCF})$ of Ni from the culture medium to shoots or roots was calculated as follows: $\mathrm{BCF}=$ shoot or root $\mathrm{Ni}$ concentration/Ni concentration in the medium.

\subsection{Sample Analyses}

To analyze the total $\mathrm{Si}, \mathrm{Ni}, \mathrm{P}, \mathrm{Fe}$, and $\mathrm{Mn}$ concentrations in the rice tissues, approximately $0.05 \mathrm{~g}$ of shoot or $0.01 \mathrm{~g}$ of root tissue was weighed into $50 \mathrm{~mL}$ centrifuge tubes (Crystalgen, Inc., Commack, NY, USA). A total of $5 \mathrm{~mL}$ of concentrated $\mathrm{HNO}_{3}$ was added to each tube and incubated overnight at $20^{\circ} \mathrm{C}$. The samples were digested using a digital block digestion system (ED54 DigiBlock; LabTech,

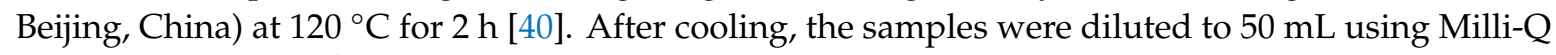
water $\left(18.2 \mathrm{M} \Omega \cdot \mathrm{cm}^{-1}\right.$; Merck Millipore, Burlington, MA, USA). The elements described above were identified using inductively coupled plasma mass spectrometry (ICP-MS; Nexion 350D; Perkin Elmer, Waltham, MA, USA). A total of $20 \mu \mathrm{g} \cdot \mathrm{L}^{-1}$ of scandium and germanium were used as internal standards. Rice flour (NIST-SRM 1568b) and GBW10010 (GSB-1) were also digested and analyzed as reference materials to ensure the results were accurate [40]. The measured values for total $\mathrm{P}\left(1551 \pm 17 \mathrm{mg} \cdot \mathrm{kg}^{-1}\right)$, Fe $\left(7.40 \pm 0.87 \mathrm{mg} \cdot \mathrm{kg}^{-1}\right)$, and Mn $\left(19.5 \pm 0.153 \mathrm{mg} \cdot \mathrm{kg}^{-1}\right)$ in SRM $1568 \mathrm{~b}$ were similar to the certified values (1530 $\pm 40 \mathrm{mg} \cdot \mathrm{kg}^{-1}, 7.42 \pm 0.44 \mathrm{mg} \cdot \mathrm{kg}^{-1}$, and $19.2 \pm 1.8 \mathrm{mg} \cdot \mathrm{kg}^{-1}$, respectively). The measured values for total $\mathrm{Ni}\left(0.245 \pm 0.012 \mathrm{mg} \cdot \mathrm{kg}^{-1}\right)$ and $\mathrm{Si}\left(231 \pm 22 \mathrm{mg} \cdot \mathrm{kg}^{-1}\right)$ in GSB-1 were lower than the certified values but within acceptable limits $\left(0.27 \pm 0.02 \mathrm{mg} \cdot \mathrm{kg}^{-1}\right.$ and $250 \pm 30 \mathrm{mg} \cdot \mathrm{kg}^{-1}$, respectively). The Ni concentrations of the nutrient solutions were also determined using ICP-MS, with scandium as an internal standard.

\subsection{Statistical Analyses}

SigmaPlot software (ver. 12.5; Systat, San Jose, CA, USA) was used to create the figures. Independent samples $t$-test, one-way analysis of variance, and post-hoc multiple comparisons (Tukey's test) were used to determine the significance $(p<0.05$ or 0.01$)$ of the results using SPSS software (ver. 20.0; IBM Corp., Armonk, NY, USA). Pearson's correlation analysis was also performed using SPSS (ver. 20.0). Redundancy analysis (RDA) was performed to analyze the relationships among the accumulation and translocation of $\mathrm{Ni}$ and other elements in the rice cultivars using Canoco software (ver. 4.5; Microcomputer Power, Ithaca, NY, USA) [43].

\section{Results}

\subsection{Accumulation and Translocation of Ni in 72 Rice Cultivars}

As shown in Figure 1, we investigated the genotypic variation among 72 rice cultivars in shoot and root $\mathrm{Ni}$ concentrations and root-to-shoot Ni translocation. After exposure to $10 \mu \mathrm{mol} \cdot \mathrm{L}^{-1} \mathrm{Ni}$ for $72 \mathrm{~h}$, significant differences were observed among the rice cultivars.

Shoot Ni concentrations varied from $13.3 \mathrm{mg} \cdot \mathrm{kg}^{-1}$ in HD5 to $29.1 \mathrm{mg} \cdot \mathrm{kg}^{-1}$ in the early rice LJ6 (geometric mean: $22.1 \mathrm{mg} \cdot \mathrm{kg}^{-1}$, median: $22.1 \mathrm{mg} \cdot \mathrm{kg}^{-1}$; Figure 1A). Root Ni concentrations varied from $385 \mathrm{mg} \cdot \mathrm{kg}^{-1}$ in YD8 to $1602 \mathrm{mg} \cdot \mathrm{kg}^{-1}$ in NJ34 (geometric mean: $715 \mathrm{mg} \cdot \mathrm{kg}^{-1}$, median: $703 \mathrm{mg} \cdot \mathrm{kg}^{-1}$; Figure 1B). The TFs of Ni from rice roots to shoots ranged from 0.011 (SJ4) to 0.058 (YD8). The translocation of Ni in rice cultivar YD8 was 5.3-fold greater than in SJ4 (Figure 1C). 


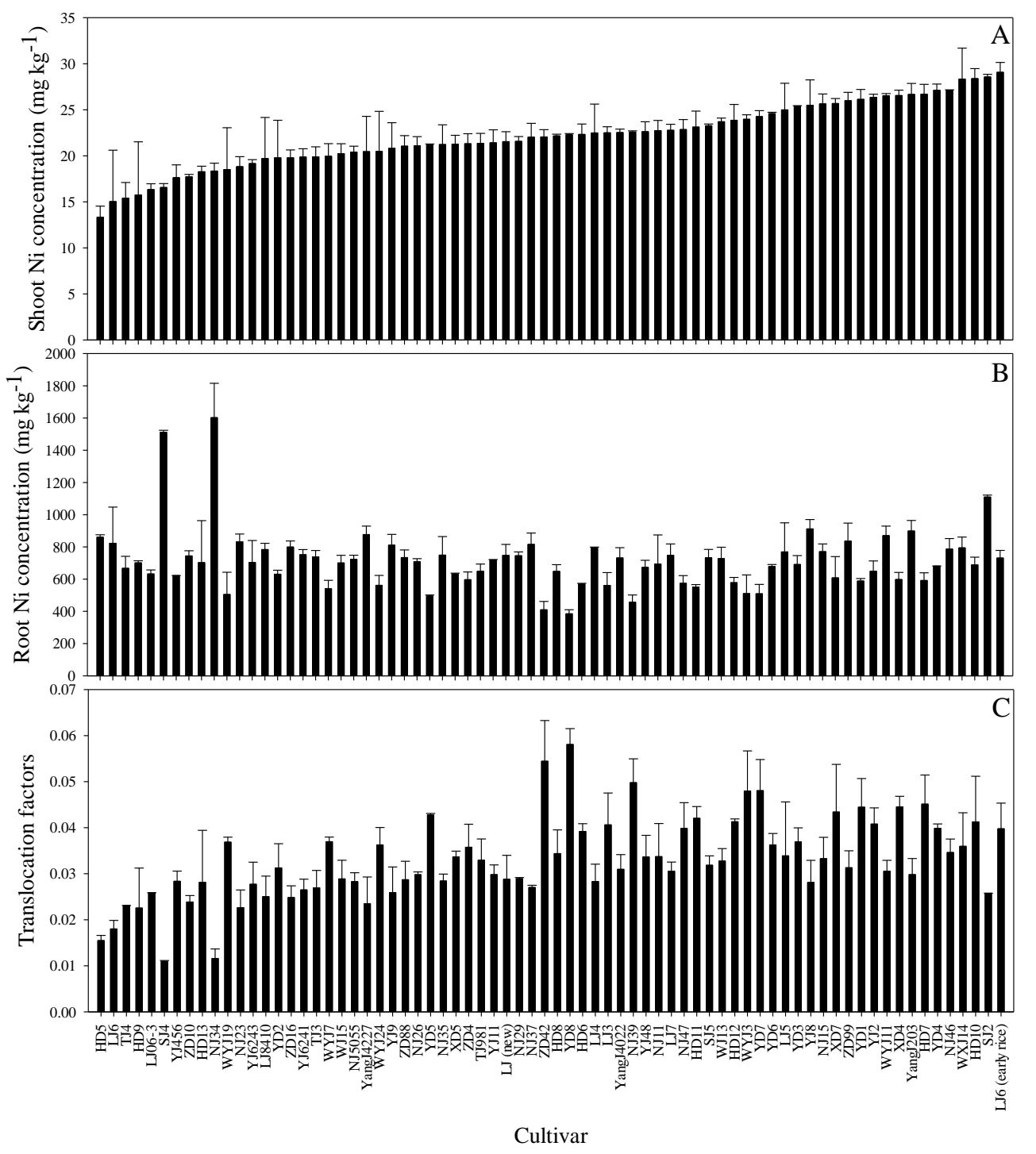

Figure 1. Nickel (Ni) concentrations in shoots $(\mathbf{A})$, roots $(\mathbf{B})$, and translocation factors $(\mathbf{C})$ of 72 different rice seedlings. Data are means \pm standard deviation $(n=3)$.

The BCFs were calculated to investigate the $\mathrm{Ni}$ accumulation capacities of shoots and roots among the rice cultivars (Figure S1). In general, the BCFs of shoots and roots differed significantly among the cultivars. The shoot Ni BCFs varied from 17.8 to 38.8, whereas the root Ni BCFs varied from 513 to 2136. HD5 had the lowest and LJ6 (early rice) had the highest shoot Ni BCFs (Figure S1A). YD8 had the lowest and NJ34 had the highest root Ni BCFs (Figure S1B).

\subsection{Variation in Shoot Ni Concentrations among Different Rice Subgroups}

Table 2 shows the 72 rice cultivars separated into 11 subgroups based on their locations within Jiangsu Province. To characterize the variation in Ni accumulation among these subgroups, we defined the 20 lowest and 20 highest shoot Ni-accumulating genotypes among the 72 cultivars as low-Ni and high-Ni cultivars, respectively. Most of the low-Ni cultivars were found in four subgroups (i.e., HD, LJ, $\mathrm{W}-\mathrm{J}$, and YJ; Table 2). In addition, the proportions of high-Ni cultivars in these four subgroups were lower compared to the proportions of low-Ni and mid-Ni cultivars $(22.2 \%, 22.2 \%, 25 \%$, and $25 \%$ of the total cultivars, respectively). Furthermore, most of the cultivars in the TJ subgroup were low-Ni cultivars, and this subgroup also had the lowest geometric mean $\left(18.9 \mathrm{mg} \cdot \mathrm{kg}^{-1}\right)$. In contrast, there were no low-Ni cultivars in the XD subgroup, which had the highest geometric mean $\left(24.5 \mathrm{mg} \cdot \mathrm{kg}^{-1}\right)$. 
Table 2. Ni concentrations in shoots of rice subgroups from Jiangsu Province.

\begin{tabular}{cccccccc}
\hline Cultivars & $\begin{array}{c}\text { Number of } \\
\text { Cultivars }\end{array}$ & $\begin{array}{c}\text { Minimum } \\
\left(\mathbf{m g} \cdot \mathbf{k g}^{-\mathbf{1}} \mathbf{)}\right.\end{array}$ & $\begin{array}{c}\text { Maximum } \\
\mathbf{( m g} \cdot \mathbf{k g}^{-\mathbf{1}} \mathbf{)}\end{array}$ & $\begin{array}{c}\text { Mean } \\
\mathbf{( m g} \cdot \mathbf{k g}^{-\mathbf{1}} \mathbf{)}\end{array}$ & \multicolumn{2}{c}{ Number of Cultivars and Proportion (\%) } \\
Low-Ni & Mid-Ni & High-Ni \\
\hline HD & 9 & $13.3 \pm 1.20$ & $28.4 \pm 1.28$ & 21.5 & $3(33.3)$ & $4(44.4)$ & $2(22.2)$ \\
LJ & 9 & $15.0 \pm 5.58$ & $29.1 \pm 1.17$ & 21.6 & $3(33.3)$ & $4(44.4)$ & $2(22.2)$ \\
NJ & 12 & $18.3 \pm 0.864$ & $27.1 \pm 0.045$ & 22.0 & $2(16.7)$ & $8(66.7)$ & $2(16.7)$ \\
SJ & 3 & $16.6 \pm 0.425$ & $28.6 \pm 0.289$ & 22.8 & $1(33.3)$ & $1(33.3)$ & $1(33.3)$ \\
TJ & 3 & $15.4 \pm 1.71$ & $21.4 \pm 1.08$ & 18.9 & $2(66.7)$ & $1(33.3)$ & - \\
W-J & 8 & $18.5 \pm 4.55$ & $28.3 \pm 3.37$ & 22.7 & $3(37.5)$ & $3(37.5)$ & $2(25)$ \\
XD & 3 & $21.3 \pm 0.958$ & $26.5 \pm 0.580$ & 24.5 & - & $1(33.3)$ & $2(66.7)$ \\
YD & 8 & $19.8 \pm 4.08$ & $27.1 \pm 0.687$ & 23.8 & $1(12.5)$ & $5(62.5)$ & $2(25)$ \\
YangJ & 3 & $20.4 \pm 3.84$ & $26.7 \pm 1.19$ & 23.2 & - & $2(66.7)$ & $1(33.3)$ \\
YJ & 8 & $17.6 \pm 1.39$ & $26.4 \pm 0.338$ & 21.7 & $3(37.5)$ & $3(37.5)$ & $2(25)$ \\
ZD & 6 & $17.7 \pm 0.267$ & $26.0 \pm 0.905$ & 21.3 & $2(33.3)$ & $3(50)$ & $1(16.7)$ \\
\hline
\end{tabular}

Note: The low Ni-accumulating (low-Ni) and high Ni-accumulating (high-Ni) cultivars are defined as the 20 lowest and 20 highest shoot Ni-accumulating genotypes among the 72 cultivars, respectively. The other 32 cultivars are defined as middle Ni-accumulating (mid-Ni) cultivars. The subgroup $\mathrm{W}-\mathrm{J}$ comprised two $\mathrm{WJ}$, five $\mathrm{WYJ}$, and one WXJ cultivars. Data are means \pm standard deviation $(n=3)$.

We also compared the shoot $\mathrm{Ni}$ concentrations of the rice cultivars with those of their parents (Table 3). The shoot Ni concentrations of HD11 and ZD16 were similar to those of their parents. In contrast, the shoot Ni concentrations of HD8 and YD8 were significantly lower than those of their parents $(p<0.05)$, whereas the shoot Ni concentration of YJ2 was significantly higher than that of its parent $(p<0.05)$.

Table 3. The Ni concentration in shoots of different rice cultivars and their parents.

\begin{tabular}{|c|c|c|c|}
\hline \multirow[t]{2}{*}{ Number } & \multicolumn{2}{|c|}{ Cultivars Abbreviation } & \multirow{2}{*}{$\begin{array}{c}\text { Shoot Ni Concentration }\left(\mathbf{m g} \cdot \mathbf{k g}^{-\mathbf{1}}\right) \\
22.2 \pm 0.190 \mathrm{~b}\end{array}$} \\
\hline & Cultivar & HD8 & \\
\hline \multirow[t]{3}{*}{1} & Maternal line (\$) & WYJ3 & $24.0 \pm 0.487 \mathrm{a}$ \\
\hline & Paternal line (बా) & WYJ3 & $24.0 \pm 0.487 \mathrm{a}$ \\
\hline & Cultivar & HD11 & $23.1 \pm 1.736 \mathrm{a}$ \\
\hline \multirow[t]{3}{*}{2} & Maternal line (\$) & HD9 & $15.7 \pm 5.78 \mathrm{a}$ \\
\hline & Paternal line (बా) & HD9 & $15.7 \pm 5.78 \mathrm{a}$ \\
\hline & Cultivar & YJ2 & $26.4 \pm 0.338 \mathrm{a}$ \\
\hline \multirow[t]{3}{*}{3} & Maternal line (\$) & NJ11 & $22.7 \pm 1.10 \mathrm{~b}$ \\
\hline & Paternal line (ब) & NJ11 & $22.7 \pm 1.10 \mathrm{~b}$ \\
\hline & Cultivar & ZD16 & $19.8 \pm 0.861 \mathrm{a}$ \\
\hline \multirow[t]{3}{*}{4} & Maternal line (\$) & ZD88 & $21.0 \pm 1.15 \mathrm{a}$ \\
\hline & Paternal line (ब) & WJ15 & $20.2 \pm 1.04 \mathrm{a}$ \\
\hline & Cultivar & ZD99 & $26.0 \pm 0.905 \mathrm{a}$ \\
\hline \multirow[t]{3}{*}{5} & Maternal line (\$) & ZD88 & $21.0 \pm 1.15 \mathrm{~b}$ \\
\hline & Paternal line (ब) & WYJ3 & $24.0 \pm 0.487 \mathrm{a}$ \\
\hline & Cultivar & YD8 & $22.3 \pm 0.128 b$ \\
\hline \multirow[t]{2}{*}{6} & Maternal line (\$) & YD6 & $24.6 \pm 0.15 \mathrm{a}$ \\
\hline & Paternal line (बా) & YD6 & $24.6 \pm 0.15 a$ \\
\hline
\end{tabular}

Note: Different lowercase letters denote significantly different at $p<0.05$ between cultivar and its parents according to a Tukey's multiple comparison test. Data are means \pm standard deviation $(n=3)$.

\subsection{Relationships between Accumulation and Translocation of $\mathrm{Si}, \mathrm{P}, \mathrm{Fe}, \mathrm{Mn}$, and $\mathrm{Ni}$ in the Rice Cultivars}

Shoot Ni concentrations were positively correlated with $\mathrm{Ni}, \mathrm{P}$, and Fe TFs $(p<0.01)$, but negatively correlated with root Fe concentrations $(p<0.01)$ (Table 4$)$. Root Ni concentrations were positively correlated with Mn TFs $(p<0.05)$, but negatively correlated with Ni TFs $(p<0.01)$, shoot Fe $(p<0.01)$, and $\mathrm{Si}$ concentrations in rice shoots and roots $(p<0.05)$. The correlation analysis also found a positive relationship between $\mathrm{Ni}$ TFs and $\mathrm{P}$ TFs, and among the concentrations of $\mathrm{Si}, \mathrm{Ni}$, and $\mathrm{Fe}$ in shoots $(p<0.01)$, but a negative relationship between Ni TFs and root Ni concentrations $(p<0.01)$. 
Table 4. Pearson correlation coefficients between accumulation and translocation of multi-element in 72 rice cultivars.

\begin{tabular}{|c|c|c|c|c|c|c|c|c|c|c|c|c|c|c|c|c|}
\hline & & \multicolumn{5}{|c|}{ Shoot Concentrations } & \multicolumn{5}{|c|}{ Root Concentrations } & \multicolumn{5}{|l|}{ TFs } \\
\hline & & Si & $\mathrm{Ni}$ & $\mathbf{P}$ & $\mathrm{Fe}$ & Mn & $\mathrm{Si}$ & $\mathrm{Ni}$ & $\mathbf{P}$ & $\mathrm{Fe}$ & Mn & $\mathrm{Si}$ & $\mathbf{N i}$ & $\mathbf{P}$ & $\mathrm{Fe}$ & Mn \\
\hline \multirow{6}{*}{$\begin{array}{l}\text { Shoot } \\
\text { concentrations }\end{array}$} & $\mathrm{Si}$ & 1 & 0.108 & $0.408^{* *}$ & $0.687^{* *}$ & 0.070 & $0.565^{* *}$ & $-0.427 * *$ & 0.196 & $0.417 * *$ & 0.336 ** & -0.216 & $0.488^{* *}$ & $0.233^{*}$ & -0.176 & -0.283 * \\
\hline & $\mathrm{Ni}$ & & 1 & 0.130 & 0.177 & -0.003 & -0.112 & -0.121 & -0.140 & $-0.335^{* *}$ & -0.003 & 0.146 & $0.574^{* *}$ & $0.343 * *$ & $0.342 * *$ & 0.076 \\
\hline & $\mathrm{P}$ & & & 1 & $0.339 * *$ & $0.302 * *$ & 0.176 & -0.187 & 0.632 ** & $0.255 *$ & 0.128 & -0.019 & 0.198 & $0.491 * *$ & -0.122 & 0.006 \\
\hline & $\mathrm{Fe}$ & & & & 1 & -0.014 & 0.140 & $-0.359 * *$ & -0.039 & 0.023 & 0.017 & 0.052 & $0.486 * *$ & $0.405^{* *}$ & $0.340^{* *}$ & -0.103 \\
\hline & $\mathrm{Mn}$ & & & & & 1 & -0.048 & 0.013 & 0.172 & $0.300 *$ & 0.081 & $0.274^{*}$ & -0.149 & 0.179 & -0.180 & $0.500^{* *}$ \\
\hline & $\mathrm{Si}$ & & & & & & 1 & -0.243 * & $0.465^{* *}$ & 0.782 ** & $0.482^{* *}$ & $-0.753^{* *}$ & 0.169 & -0.311 ** & $-0.701^{* *}$ & $-0.418^{* *}$ \\
\hline \multirow{3}{*}{$\begin{array}{l}\text { Root } \\
\text { concentrations }\end{array}$} & $\mathrm{Ni}$ & & & & & & & 1 & -0.087 & -0.173 & -0.153 & 0.085 & $-0.767^{* *}$ & -0.116 & 0.129 & $0.299 *$ \\
\hline & $\mathrm{P}$ & & & & & & & & 1 & $0.496^{* *}$ & $0.377^{* *}$ & $-0.311^{* *}$ & -0.086 & $-0.350^{* *}$ & $-0.502^{* *}$ & -0.209 \\
\hline & $\mathrm{Mn}$ & & & & & & & & & & 1 & -0.212 & 0.094 & $-0.236^{*}$ & $-0.296 *$ & $-0.707 * *$ \\
\hline \multirow{5}{*}{ TFs } & $\mathrm{Si}$ & & & & & & & & & & & 1 & -0.046 & $0.330 * *$ & $0.604^{* *}$ & $0.364^{* *}$ \\
\hline & $\mathrm{Ni}$ & & & & & & & & & & & & 1 & $0.336^{* *}$ & 0.186 & -0.231 \\
\hline & $\mathrm{P}$ & & & & & & & & & & & & & 1 & $0.427 * *$ & $0.240 *$ \\
\hline & $\mathrm{Fe}$ & & & & & & & & & & & & & & 1 & 0.200 \\
\hline & $\mathrm{Mn}$ & & & & & & & & & & & & & & & 1 \\
\hline
\end{tabular}

Note: The translocation factor of $\mathrm{Si}, \mathrm{Ni}, \mathrm{P}, \mathrm{Fe}$, and $\mathrm{Mn}$
$* *$ Correlation is significant at the 0.01 level (two-tailed) 
Among the 20 low-Ni cultivars, we observed a positive relationship between shoot $\mathrm{Ni}$ concentrations and Ni TFs ( $p<0.05$; Table S1). However, there was no such relationship among the 20 high-Ni cultivars (Table S2). In these high-Ni cultivars, shoot Ni concentrations were positively correlated with Mn TFs $(p<0.05)$. Root Ni concentrations were negatively correlated with Ni TFs in both low-Ni and high-Ni cultivars $(p<0.01)$. In addition, root Ni concentrations were positively correlated with Fe TFs and Mn TFs in low-Ni and high-Ni cultivars, respectively (both, $p<0.05$; Tables S1 and S2). The Ni TFs were positively correlated with shoot Si concentrations in both low-Ni and high-Ni cultivars $(p<0.05)$. Furthermore, the Ni TFs were positively correlated with shoot Fe concentrations in high-Ni cultivars $(p<0.05)$, but the correlation coefficients were not significant for the low-Ni cultivars.

\subsection{Relationships among the Accumulation and Translocation of Ni and Other Elements in the Rice Subgroups}

Both the first canonical axis and all canonical axes explained a significant amount of the variation $(p=0.004$ and $p=0.002$, respectively) based on the Monte Carlo permutation test (number of permutations $=499$; Figure 2). The first and second axes contributed $29.1 \%$ and $9.7 \%$ of the total variation, respectively. For $\mathrm{Ni}$ accumulation (displayed as shoot $\mathrm{Ni}$ and root $\mathrm{Ni}$ concentrations) and translocation (displayed as Ni TFs), shoot $\mathrm{Si}(p=0.002 ; \mathrm{F}=14.39)$ and root $\mathrm{Fe}(p=0.008 ; \mathrm{F}=6.00)$ concentrations accounted for the variation among the 72 rice cultivars. Shoot $\mathrm{Si}$ concentrations explained the greatest proportion of this variation (17\%), followed by root Fe concentrations $(7 \%)$.

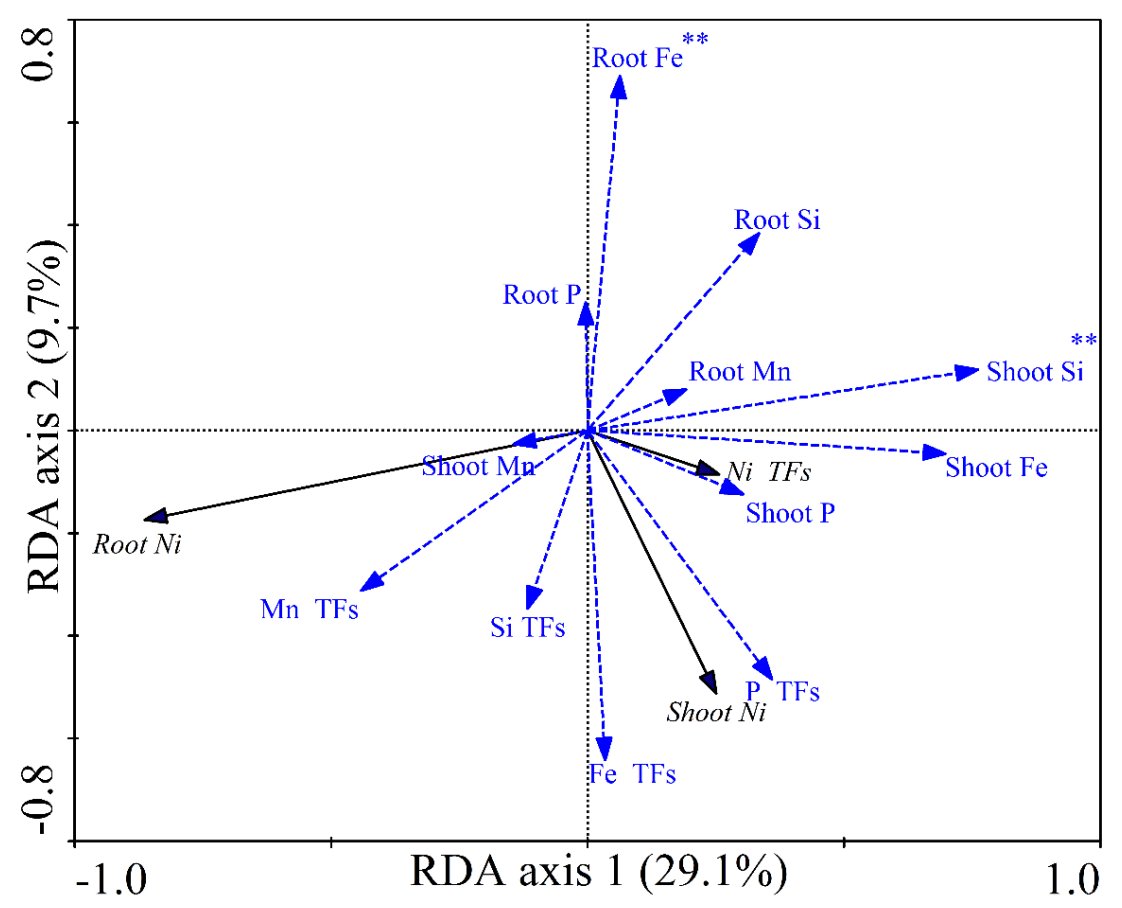

Figure 2. RDA (Redundancy analysis) ordination diagrams of the relationships between accumulation and translocation of $\mathrm{Ni}$ and multi-element concentrations in 72 rice cultivars. Shoot $\mathrm{Ni}$, root $\mathrm{Ni}$, and $\mathrm{Ni}$ TFs (translocation factors) are represented by black lines with arrows. Shoot $\mathrm{Si}$, shoot $\mathrm{P}$, shoot $\mathrm{Fe}$, shoot $\mathrm{Mn}$, root $\mathrm{Si}$, root $\mathrm{P}$, root Fe, root Mn, Si TFs, P TFs, Fe TFs, and Mn TFs are represented by blue lines with arrows. ${ }^{* *}(p<0.01)$ represent significant factors influencing $\mathrm{Ni}$ accumulation and translocation based on Monte Carlo analysis (the number of permutations $=499$ ).

An RDA of the relationships among accumulation and translocation of $\mathrm{Ni}$ and multi-element concentrations in the 20 lowest and 20 highest Ni-accumulating rice cultivars is shown in Figure 3. The high-Ni rice cultivars mainly clustered in the left upper and lower quadrants, whereas the low-Ni rice cultivars clustered in the lower right and left quadrants. The first and second RDA axes accounted 
for $21.9 \%$ and $17.0 \%$ of the total variation, respectively (both, $p=0.002$ ). The shoot $\mathrm{Si}$ and P TFs accounted for $12 \%$ and $15 \%$ of the $\mathrm{Ni}$ accumulation and translocation variation, respectively (both, $p<0.01)$.

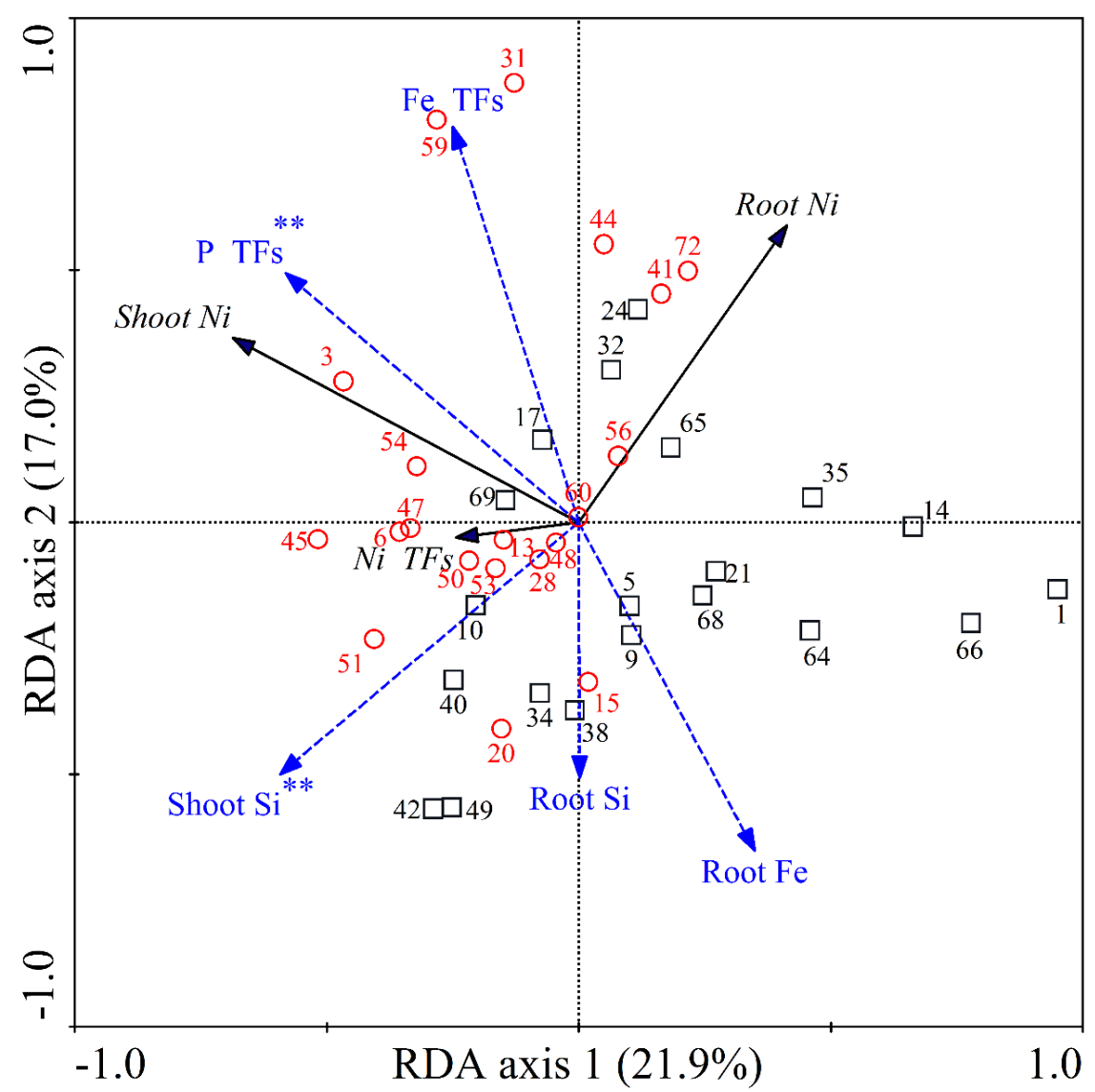

Figure 3. RDA ordination diagrams of the relationships among $\mathrm{Ni}$ and multi-element uptake and translocation in 40 rice cultivars. Shoot $\mathrm{Ni}$, root Ni, and Ni TFs are displayed as black lines with arrows. Shoot $\mathrm{Si}$, root $\mathrm{Si}$, root $\mathrm{Fe}, \mathrm{P}$ TFs, and Fe TFs are represented by blue lines with arrows. The 20 lowest Ni-accumulating rice cultivars are represented by squares “ $\square$ ". The 20 highest Ni-accumulating rice cultivars are represented by circles " $\bigcirc$ ". The numbers around the squares or circles represent 40 associated rice cultivars listed in Table 1. ${ }^{* *}(p<0.01)$ represent significant factors influencing Ni accumulation and translocation based on Monte Carlo analysis (the number of permutations $=499$ ).

The first and second axes accounted for $75.7 \%$ and $4.5 \%$ of the total variation among the 20 lowest Ni-accumulating rice cultivars, respectively $(p=0.002$; Figure S2). The Si TFs, root Fe and shoot Fe concentrations, and P TFs accounted for $40 \%, 11 \%, 9 \%$, and $6 \%$ of the variation in $\mathrm{Ni}$ accumulation and translocation, respectively (all, $p<0.05$ ). In contrast, an RDA analysis of the relationships among $\mathrm{Ni}$ accumulation, translocation and multi-element concentrations in the 20 high-Ni rice cultivars is not shown because the Monte Carlo tests of the first canonical axis and all canonical axes were not significant ( $p=0.218$ and $p=0.23$, respectively).

\subsection{Effects of Ni Exposure on Rice Seedling Growth}

We also investigated the effects of $\mathrm{Ni}$ exposure on rice growth, under hydroponic conditions. The five lowest and highest shoot $\mathrm{Ni}$ accumulating genotypes were selected from among the 72 cultivars, and the effect on biomass (dry weight) of providing $10 \mu \mathrm{mol} \cdot \mathrm{L}^{-1} \mathrm{Ni}$ was analyzed (Figure S3). No significant differences in shoot (Figure S3A,B) or root (Figure S3C,D) biomass were observed in any 
of the ten cultivars. Similar results were observed for the remaining 62 cultivars (data not shown). These results suggest that exposure to Ni for 3 days did not significantly affect rice seedling growth.

\subsection{Effects of Ni Exposure on Multi-Element Uptake}

To further investigate the effects of $\mathrm{Ni}$ exposure on the uptake of nutrients, we analyzed the presences of multiple elements in rice shoots and roots after exposure to $10 \mu \mathrm{mol} \cdot \mathrm{L}^{-1} \mathrm{Ni}$ for 3 days. In general, the uptake of $\mathrm{Si}, \mathrm{P}, \mathrm{Fe}$, and $\mathrm{Mn}$ in rice shoots and roots decreased in response to $\mathrm{Ni}$ exposure. In addition, $\mathrm{Ni}$ exposure had a much greater effect on multi-element uptake in the shoots of the five highest $\mathrm{Ni}$-accumulating cultivars than in those of the five lowest $\mathrm{Ni}$-accumulating cultivars (Figures $\mathrm{S} 4$ and S5). Among the low-Ni cultivars, the uptakes of $\mathrm{Si}$ and Fe were considerably more affected by $\mathrm{Ni}$ exposure than those of $\mathrm{P}$ and Mn (Figure S4). In addition, the Mn uptake in shoots and roots of the five high-Ni cultivars decreased significantly (Figure S5). Furthermore, in roots exposed to Ni, Fe concentrations were much higher than Mn concentrations in both low-Ni and high-Ni cultivars. Conversely, in rice shoots, Mn concentrations were much higher than Fe concentrations (Figures S4 and S5).

\section{Discussion}

$\mathrm{Ni}$ is the major PTE pollutant present in rice grains $[9,20]$, and rice is a major dietary source of $\mathrm{Ni}$ for the Chinese population, particularly children aged 2-11 years and Ni-sensitive individuals [20]. However, strategies to decrease $\mathrm{Ni}$ accumulation in rice have received little attention until now. Many studies have shown that the concentrations of PTEs (e.g., $\mathrm{Cd}, \mathrm{As}, \mathrm{Pb}$, and $\mathrm{Ni}$ ) in grains from various rice subpopulations differ significantly $[12,20,44,45]$. Therefore, it may be possible to identify cultivars that accumulate significantly lower levels of Ni. In China, approximately $7.4 \%$ of the total rice-planting area is located in Jiangsu Province and 90\% of the rice grown is of the japonica variety [46]. In this study, we investigated $\mathrm{Ni}$ accumulation and translocation in 72 major rice cultivars, as well as multi-element uptake and translocation in different rice tissues. Our results may be used to prevent excessive $\mathrm{Ni}$ accumulation in rice grown in Ni-contaminated soil and to improve food safety.

There were significant differences in $\mathrm{Ni}$ accumulation and translocation across the 72 major rice cultivars after 3 days of $\mathrm{Ni}$ exposure (Figure 1 ). Shoot $\mathrm{Ni}$ concentrations were positively correlated with Ni TFs $(p<0.01)$, but not with root $\mathrm{Ni}$ in all rice cultivars (Table 4). Therefore, differences in shoot $\mathrm{Ni}$ concentrations were explained by the different $\mathrm{Ni}$-transport capacities of the rice genotypes rather than the immobilization of $\mathrm{Ni}$ in roots in response to Ni exposure. Previous studies have shown that phytochelatins (PCs) are important for PTE detoxification in plants [47,48]. However, in contrast to responses induced by PTEs such as $\mathrm{Cd}$ and As (including arsenite and trivalent methylarsonous acid) [48], PC synthesis was not strongly induced by Ni [47,49], suggesting that PC synthesis and subsequent $\mathrm{Ni}$ sequestration in roots are less important for Ni detoxification. Similar results were also observed in low-Ni (20 lowest shoot Ni BCFs; Figure S1A) and high-Ni (20 highest shoot Ni BCFs; Figure S1A) cultivars. The geometric means of shoot Ni concentrations $\left(26.5 \pm 1.33 \mathrm{mg} \cdot \mathrm{kg}^{-1}\right)$ and Ni TFs $(0.037 \pm 0.006)$ in high-Ni cultivars were significantly $(p<0.001)$ greater than those of low-Ni cultivars $\left(18.0 \pm 1.99 \mathrm{mg} \cdot \mathrm{kg}^{-1}\right.$ and $0.025 \pm 0.007$, respectively; Figure 1A,C). However, the root Ni concentrations of low-Ni $\left(792 \pm 278 \mathrm{mg} \cdot \mathrm{kg}^{-1}\right)$ and high-Ni cultivars $\left(738 \pm 142 \mathrm{mg} \cdot \mathrm{kg}^{-1}\right)$ were not significantly different (Figure 1B). These results suggest that the high-Ni cultivars translocate Ni to shoots more effectively than low-Ni cultivars. In addition, although root $\mathrm{Ni}$ sequestration is not the most important factor affecting shoot $\mathrm{Ni}$ concentrations, root $\mathrm{Ni}$ concentrations were negatively correlated with Ni TFs in both low-Ni and high-Ni cultivars ( $p<0.01$; Tables S1 and S2). These observations suggest that cultivars that sequester greater concentrations of $\mathrm{Ni}$ in their roots can decrease $\mathrm{Ni}$ translocation to their shoots.

To further identify the major factors that affect the uptake and translocation of $\mathrm{Ni}$ in different rice genotypes, RDA was used to analyze the relationships among the accumulation and translocation of Ni and other elements in rice tissues (Figure 2, Figure 3 and Figure S2). The results showed that shoot $\mathrm{Si}$ and root Fe concentrations significantly affected $\mathrm{Ni}$ accumulation and translocation in 
the 72 cultivars studied ( $p<0.01$; Figure 2). Therefore, the uptake and transport of Ni is closely associated with $\mathrm{Si}$ and Fe concentrations. $\mathrm{Si}$ is an important nutrient for rice growth $[25,50]$ and also protects plants from toxic metals such as $\mathrm{Cd}, \mathrm{As}, \mathrm{Ni}$, and $\mathrm{Zn}$ by enhancing growth and photosynthetic carbon fixation, and suppressing the uptake of toxic metals [31,51-53]. Therefore, rice cultivars with a greater capacity for $\mathrm{Si}$ assimilation may also accumulate less $\mathrm{Ni}$ in their shoots and roots. In addition, the geometric mean of root $\mathrm{Si}$ concentrations was significantly greater in the five low-Ni cultivars than in the five high-Ni cultivars, regardless of whether the plants were exposed to $\mathrm{Ni}(p<0.05$; Figures S4 and S5). Furthermore, root Fe concentrations were correlated with Ni uptake and transport in rice ( $p<0.01$; Figure 2 and Figure S2). Interestingly, Fe plaque deposits, which are visible as a reddish-brown coating on the surface of roots, can sequestrate PTEs such as $\mathrm{Cd}$, As, and $\mathrm{Ni}$ and reduce their toxicity $[34,38,54]$. However, we found no evidence of $\mathrm{Ni}$ and Fe co-precipitation on the surface of roots, and no significant correlations between root $\mathrm{Fe}$ and root $\mathrm{Ni}$ concentrations were observed (Table 4, Tables S1, and S2). The excess $\mathrm{P}$ in the culture medium (i.e., $5 \mathrm{mg} \mathrm{L}^{-1} \mathrm{P}$ for 3 days) might be responsible for the results because previous studies have demonstrated that iron plaque is induced by P starvation [33]. Nonetheless, Fe accumulation in rice roots was correlated with the uptake and transport of $\mathrm{Si}$ in the 72 cultivars $(p<0.01$; Table 4$)$, and this may have an indirect effect on the uptake and transport of Ni in rice. Similarly, indirect effects of P TFs on the uptake and transport of Ni among 20 low-Ni and high-Ni cultivars were also observed (Figure 3), because P TFs were correlated with the uptake and transport of Si and Fe but not Ni (Tables S1 and S2).

Our results indicated that the uptake of nutrient elements was inhibited in rice under Ni stress. Figures S4 and S5 show that the concentrations of most nutrient elements in rice shoots and roots decrease after exposure to Ni for 3 days in both low-Ni and high-Ni cultivars. Differences in shoot or root element concentrations in response to $\mathrm{Ni}$ exposure were probably due to $\mathrm{Ni}$ rather than a difference in rice growth, because no differences were observed in shoot (Figure S4A,B) or root (Figure S4C,D) biomass after $72 \mathrm{~h}$ of Ni exposure. Similar results were obtained from other rice studies, which showed decreased $\mathrm{K}, \mathrm{Ca}, \mathrm{Mg}$, Fe, and Mn uptake and distribution $[49,55,56]$. This may be due to alterations in root membrane permeability in response to excessive exposure to Ni [55]. Furthermore, our data suggest that the high-Ni rice cultivars were much more sensitive to Ni than the low-Ni cultivars, especially with respect to accumulation of $\mathrm{Si}$ and $\mathrm{Mn}$ in rice shoots (Figures S4 and S5). This may be crucial for the enhanced shoot $\mathrm{Ni}$ accumulation in high-Ni cultivars because these nutrients are essential for rice growth and are also important for alleviating PTEs toxicity [31,57].

We showed that genotype has a significant effect on shoot Ni concentrations among the different rice subgroups (Table 2). In addition, significant differences among cultivars were found within the same subgroup. For example, among the 72 cultivars, those with the lowest (HD5 and LJ6) and highest (HD10 and LJ6: early rice) concentrations of $\mathrm{Ni}$ in their shoot were found in the same subgroups (HD and LJ). Genetic differences in the parent plants may be responsible for differences in the PTE accumulation capacities of different rice cultivars [20,58]. However, it is unclear how genotype affects $\mathrm{Ni}$ accumulation. Some studies have suggested that progeny plants inherit genes that decrease the accumulation of PTEs from parent plants that also show low levels of PTE accumulation [59,60]. Although cultivar YJ2 exhibited a greater capacity for Ni accumulation than its parent, other cultivars (e.g., HD8 and YD8) exhibited a similar capacity for decreased Ni accumulation to their parents (Table 3), indicating that it should be possible to breed rice that accumulates lower levels of $\mathrm{Ni}$. The four subgroups with the greatest number of low-Ni cultivars (i.e., HD, LJ, W-J, and YJ) are shown in Table 2 and these may be used to further investigate the genetics underpinning low-Ni accumulation.

\section{Conclusions}

This study demonstrates that genotype had a significant effect on Ni accumulation and translocation in a population of 72 rice cultivars. The variation in the shoot $\mathrm{Ni}$ concentrations was explained by different capacities for $\mathrm{Ni}$ transport in different rice genotypes rather than by the immobilization of $\mathrm{Ni}$ in roots exposed to high Ni concentrations. In general, the Ni TFs of high-Ni cultivars were significantly 
greater than those of low-Ni cultivars. The RDA of the 72 rice genotypes suggested that the uptake of $\mathrm{Si}$ and Fe was the major factor affecting the accumulation and translocation of Ni. However, significant differences were also observed between 20 low-Ni and 20 high-Ni rice cultivars. Among the 20 low-Ni cultivars, $\mathrm{Si}$ TFs accounted for most of the variation in Ni accumulation and translocation. However, $\mathrm{P}$ TFs accounted for most of the variation in $\mathrm{Ni}$ uptake and translocation observed between the 20 low-Ni and 20 high-Ni cultivar groups. Mn was less important than $\mathrm{Si}, \mathrm{Fe}$, and $\mathrm{P}$ in influencing $\mathrm{Ni}$ accumulation and translocation in these cultivars. The results of this study may be used to prevent excessive $\mathrm{Ni}$ accumulation in rice grown in Ni-contaminated environments. Further studies are needed to investigate how genotypes influence $\mathrm{Ni}$ uptake and transport in rice.

Supplementary Materials: The following are available online at http://www.mdpi.com/1660-4601/16/18/3281/s1, Figure S1: Nickel (Ni) bioconcentration factors in the rice shoots (A) and roots (B). The bioconcentration factor $(\mathrm{BCF})$ of $\mathrm{Ni}$ from culture medium to shoots or roots were calculated as: $\mathrm{BCF}=\mathrm{Cshoots} \mathrm{Ni}$ or roots $\mathrm{Ni} / \mathrm{CNi}$ in culture medium, Figure S2: RDA ordination diagrams of the relationships between accumulation and translocation of $\mathrm{Ni}$ and multi-element ( $\mathrm{Si}, \mathrm{P}, \mathrm{Fe}$, and $\mathrm{Mn}$ ) in 20 lowest Ni-accumulating rice cultivars, Figure S3: The biomass (dry weights) of rice seedlings after exposure to 0 and $10 \mu \mathrm{mol} \cdot \mathrm{L}^{-1} \mathrm{Ni}$ for 3 days under hydroponics condition, Figure S4: The amount of nutrients in rice shoots and roots with or without addition of $10 \mu \mathrm{mol} \cdot \mathrm{L}^{-1} \mathrm{Ni}$ for 3 days under hydroponics condition, Figure S5: The amount of nutrients in rice shoots and roots with or without addition of $10 \mu \mathrm{mol} \cdot \mathrm{L}^{-1} \mathrm{Ni}$ for 3 days under hydroponics condition, Table S1: Pearson correlation coefficients between accumulation and translocation of multi-element ( $\mathrm{Si}, \mathrm{Ni}, \mathrm{P}, \mathrm{Fe}$, and $\mathrm{Mn}$ ) in 20 lowest Ni-accumulating rice cultivars, Table S2: Pearson correlation coefficients between accumulation and translocation of multi-element $(\mathrm{Si}, \mathrm{Ni}, \mathrm{P}, \mathrm{Fe}$, and $\mathrm{Mn}$ ) in 20 highest $\mathrm{Ni}$-accumulating rice cultivars.

Author Contributions: Data curation, Y.W.; Formal analysis, Y.W., C.S., K.L., Y.L., J.C., and X.C.; Funding acquisition, Y.W. and X.Y.; Resources, X.F. and X.Y.; Software, J.C. and X.C.; Writing-review and editing, Y.W. and X.Y.

Funding: This research is supported by the National Natural Science Foundation of China $(41701373,31772197)$, China Postdoctoral Science Foundation funded project (2017M621667) and Open Foundation of Jiangsu Key Laboratory for Food Quality and Safety-State Key Laboratory Cultivation Base (028074911709).

Conflicts of Interest: The authors declare no conflict of interest.

\section{References}

1. Sreekanth, T.V.M.; Nagajyothi, P.C.; Lee, K.D.; Prasad, T.N. Occurrence, physiological responses and toxicity of nickel in plants. Int. J. Environ. Sci. Technol. 2013, 10, 1129-1140. [CrossRef]

2. Buxton, S.; Garman, E.; Heim, K.E.; Lyons-Darden, T.; Schlekat, C.E.; Taylor, M.D.; Oller, A.R. Concise review of nickel human health toxicology and ecotoxicology. Inorganics 2019, 7, 89. [CrossRef]

3. Rizwan, M.; Mostofa, M.G.; Ahmad, M.Z.; Imtiaz, M.; Mehmood, S.; Adeel, M.; Dai, Z.; Li, Z.; Aziz, O.; Zhang, Y.; et al. Nitric oxide induces rice tolerance to excessive nickel by regulating nickel uptake, reactive oxygen species detoxification and defense-related gene expression. Chemosphere 2018, 191, 23-35. [CrossRef]

4. Ministry of Environmental Protection. The Ministry of Land and Resources Report on the National Soil Contamination Survey; Ministry of Environmental Protection: Beijing, China, 2014.

5. Liao, Q.L.; Hua, M.; Jin, Y.; Huang, S.S.; Zhu, B.W.; Weng, Z.H.; Pan, Y.M. A preliminary study of the distribution and pollution source of heavy metals in soils of Jiangsu Province. Geol. China 2009, 36, 1163-1174.

6. Jiang, Y.; Chao, S.; Liu, J.; Yang, Y.; Chen, Y.; Zhang, A.; Cao, H. Source apportionment and health risk assessment of heavy metals in soil for a township in Jiangsu Province, China. Chemosphere 2017, 168, 1658-1668. [CrossRef]

7. Rizwan, M.; Imtiaz, M.; Dai, Z.; Mehmood, S.; Adeel, M.; Liu, J.; Tu, S. Nickel stressed responses of rice in Ni subcellular distribution, antioxidant production, and osmolyte accumulation. Environ. Sci. Pollut. Res. 2017, 24, 20587-20598. [CrossRef]

8. Hseu, Z.Y.; Lai, Y.J. Nickel accumulation in paddy rice on serpentine soils containing high geogenic nickel contents in Taiwan. Environ. Geochem. Health 2017, 39, 1325-1334. [CrossRef]

9. Naseri, M.; Vazirzadeh, A.; Kazemi, R.; Zaheri, F. Concentration of some heavy metals in rice types available in Shiraz market and human health risk assessment. Food Chem. 2015, 175, 243-248. [CrossRef]

10. Chen, H.; Tang, Z.; Wang, P.; Zhao, F.J. Geographical variations of cadmium and arsenic concentrations and arsenic speciation in Chinese rice. Environ. Pollut. 2018, 238, 482-490. [CrossRef] 
11. Wang, L.; Gao, S.; Yin, X.; Yu, X.; Luan, L. Arsenic accumulation, distribution and source analysis of rice in a typical growing area in north China. Ecotoxicol. Environ. Saf. 2019, 167, 429-434. [CrossRef]

12. Norton, G.J.; Pinson, S.R.; Alexander, J.; McKay, S.; Hansen, H.; Duan, G.L.; Rafiqul Islam, M.; Islam, S.; Stroud, J.L.; Zhao, F.J.; et al. Variation in grain arsenic assessed in a diverse panel of rice (Oryza sativa) grown in multiple sites. New Phytol. 2012, 193, 650-664. [CrossRef]

13. Williams, P.N.; Islam, S.; Islam, R.; Jahiruddin, M.; Adomako, E.; Soliaman, A.R.M.; Rahman, G.K.M.M.; Lu, Y.; Deacon, C.; Zhu, Y.G.; et al. Arsenic limits trace mineral nutrition (selenium, zinc, and nickel) in Bangladesh Rice Grain. Environ. Sci. Technol. 2009, 43, 8430-8436. [CrossRef]

14. Liu, J.; Qian, M.; Cai, G.; Yang, J.; Zhu, Q. Uptake and translocation of Cd in different rice cultivars and the relation with Cd accumulation in rice grain. J. Hazard. Mater. 2007, 143, 443-447. [CrossRef]

15. Maheshwari, R.; Dubey, R.S. Nickel-induced oxidative stress and the role of antioxidant defence in rice seedlings. Plant Growth Regul. 2009, 59, 37-49. [CrossRef]

16. Maheshwari, R.; Dubey, R.S. Inhibition of ribonuclease and protease activities in germinating rice seeds exposed to nickel. Acta Physiol. Plant. 2008, 30, 863. [CrossRef]

17. Mishra, P.; Dubey, R.S. Excess nickel modulates activities of carbohydrate metabolizing enzymes and induces accumulation of sugars by upregulating acid invertase and sucrose synthase in rice seedlings. Biometals 2013, 26, 97-111. [CrossRef]

18. Li, Z.; Su, H.; Wang, L.; Hu, D.; Zhang, L.; Fang, J.; Jin, M.; Fiati Kenston, S.S.; Song, X.; Shi, H.; et al. Epidemiological study on metal pollution of Ningbo in China. Int. J. Environ. Res. Public Health 2018, 15, 424. [CrossRef]

19. European Commission. Commission Regulation (EC) No 1881/2006 of 19 December 2006 setting maximum levels for certain contaminants in foodstuffs. Off. J. Eur Union 2006, 364, 5-24.

20. Cao, Z.; Mou, R.; Cao, Z.; Lin, X.; Xu, P.; Chen, Z.; Zhu, Z.; Chen, M. Nickel in milled rice (Oryza sativa L.) from the three main rice-producing regions in China. Food Addit. Contam. B 2017, 10, 69-77. [CrossRef]

21. Rose, M.; Baxter, M.; Brereton, N.; Baskaran, C. Dietary exposure to metals and other elements in the 2006 UK Total Diet Study and some trends over the last 30 years. Food Addit. Contam. Part A 2010, 27, 1380-1404. [CrossRef]

22. Race, M.; Ferraro, A.; Fabbricino, M.; La Marca, A.; Panico, A.; Spasiano, D.; Tognacchini, A.; Pirozzi, F. Ethylenediamine- $N, N^{\prime}$-disuccinic acid (EDDS)—Enhanced flushing optimization for contaminated agricultural soil remediation and assessment of prospective $\mathrm{Cu}$ and $\mathrm{Zn}$ transport. Int. J. Environ. Res. Public Health 2018, 15, 543. [CrossRef]

23. Yang, X.; Ye, Z.; Shi, C.H.; Zhu, M.; Graham, R. Genotypic differences in concentrations of iron, manganese, copper, and zinc in polished rice grains. J. Plant Nutr. 1998, 21, 1453-1462. [CrossRef]

24. Norton, G.J.; Islam, M.R.; Deacon, C.M.; Zhao, F.J.; Stroud, J.L.; McGrath, S.P.; Islam, S.; Jahiruddin, M.; Feldmann, J.; Price, A.H.; et al. Identification of low inorganic and total grain arsenic rice cultivars from Bangladesh. Environ. Sci. Technol. 2009, 43, 6070-6075. [CrossRef]

25. Yamaji, N.; Mitatni, N.; Ma, J.F. A Transporter Regulating Silicon Distribution in Rice Shoots. Plant Cell 2008, 20, 1381. [CrossRef]

26. Rose, T.J.; Pariasca-Tanaka, J.; Rose, M.T.; Fukuta, Y.; Wissuwa, M. Genotypic variation in grain phosphorus concentration, and opportunities to improve P-use efficiency in rice. Field Crop. Res. 2010, 119, 154-160. [CrossRef]

27. Li, R.; Stroud, J.; Ma, J.; McGrath, S.; Zhao, F. Mitigation of arsenic accumulation in rice with water management and silicon fertilization. Environ. Sci. Technol. 2009, 43, 3778-3783. [CrossRef]

28. Khan, M.A.; Stroud, J.L.; Zhu, Y.G.; McGrath, S.P.; Zhao, F.J. Arsenic bioavailability to rice is elevated in Bangladeshi paddy soils. Environ. Sci. Technol. 2010, 44, 8515-8521. [CrossRef]

29. Zhao, F.; Ma, J.; Meharg, A.; McGrath, S. Arsenic uptake and metabolism in plants. New Phytol. 2009, 181, 777-794. [CrossRef]

30. Kamiya, T.; Islam, R.; Duan, G.; Uraguchi, S.; Fujiwara, T. Phosphate deficiency signaling pathway is a target of arsenate and phosphate transporter OsPT1 is involved in As accumulation in shoots of rice. Soil Sci. Plant Nutr. 2013, 59, 580-590. [CrossRef]

31. Zhang, C.; Wang, L.; Nie, Q.; Zhang, W.; Zhang, F. Long-term effects of exogenous silicon on cadmium translocation and toxicity in rice (Oryza sativa L.). Environ. Exp. Bot. 2008, 62, 300-307. [CrossRef] 
32. Yang, Y.; Chen, R.; Fu, G.; Xiong, J.; Tao, L. Phosphate deprivation decreases cadmium (Cd) uptake but enhances sensitivity to $\mathrm{Cd}$ by increasing iron ( $\mathrm{Fe}$ ) uptake and inhibiting phytochelatins synthesis in rice (Oryza sativa). Acta Physiol. Plant. 2016, 38, 28. [CrossRef]

33. Liu, W.J.; Zhu, Y.G.; Smith, F.A.; Smith, S.E. Do phosphorus nutrition and iron plaque alter arsenate (As) uptake by rice seedlings in hydroponic culture? New Phytol. 2004, 162, 481-488. [CrossRef]

34. Liu, W.J.; Zhu, Y.G.; Smith, F. Effects of iron and manganese plaques on arsenic uptake by rice seedlings (Oryza sativa L.) grown in solution culture supplied with arsenate and arsenite. Plant Soil 2005, 277, 127-138. [CrossRef]

35. Hossain, M.; Jahiruddin, M.; Panaullah, G.; Loeppert, R.; Islam, M.; Duxbury, J. Spatial variability of arsenic concentration in soils and plants, and its relationship with iron, manganese and phosphorus. Environ. Pollut. 2008, 156, 739-744. [CrossRef]

36. Liu, J.; Cao, C.; Wong, M.; Zhang, Z.; Chai, Y. Variations between rice cultivars in iron and manganese plaque on roots and the relation with plant cadmium uptake. J. Environ. Sci. China 2010, 22, 1067-1072. [CrossRef]

37. Liu, H.J.; Zhang, J.L.; Zhang, F.S. Role of iron plaque in Cd uptake by and translocation within rice (Oryza sativa L.) seedlings grown in solution culture. Environ. Exp. Bot. 2007, 59, 314-320. [CrossRef]

38. Greipsson, S.; Crowder, A. Amelioration of copper and nickel toxicity by iron plaque on roots of rice (Oryza sativa). Can. J. Bot. 1992, 70, 824-830. [CrossRef]

39. Cheng, H.; Wang, M.; Wong, M.H.; Ye, Z. Does radial oxygen loss and iron plaque formation on roots alter $\mathrm{Cd}$ and $\mathrm{Pb}$ uptake and distribution in rice plant tissues? Plant Soil 2014, 375, 137-148. [CrossRef]

40. Wang, Y.; Li, Y.Q.; Lv, K.; Cheng, J.J.; Chen, X.L.; Ge, Y.; Yu, X.Y. Soil microalgae modulate grain arsenic accumulation by reducing dimethylarsinic acid and enhancing nutrient uptake in rice (Oryza sativa L.). Plant Soil 2018, 430, 99-111. [CrossRef]

41. Ren, J.H.; Ma, L.Q.; Sun, H.J.; Cai, F.; Luo, J. Antimony uptake, translocation and speciation in rice plants exposed to antimonite and antimonate. Sci. Total Environ. 2014, 475, 83-89. [CrossRef]

42. Chen, X.; Li, H.; Chan, W.F.; Wu, C.; Wu, F.; Wu, S.; Wong, M.H. Arsenite transporters expression in rice (Oryza sativa L.) associated with arbuscular mycorrhizal fungi (AMF) colonization under different levels of arsenite stress. Chemosphere 2012, 89, 1248-1254. [CrossRef]

43. Zhao, Z.; Dong, S.; Jiang, X.; Zhao, J.; Liu, S.; Yang, M.; Han, Y.; Sha, W. Are land use and short time climate change effective on soil carbon compositions and their relationships with soil properties in alpine grassland ecosystems on Qinghai-Tibetan Plateau? Sci. Total Environ. 2018, 625, 539-546. [CrossRef]

44. Meharg, A.A.; Williams, P.N.; Adomako, E.; Lawgali, Y.Y.; Deacon, C.; Villada, A.; Cambell, R.C.; Sun, G.; Zhu, Y.G.; Feldmann, J. Geographical variation in total and inorganic arsenic content of polished (white) rice. Environ. Sci. Technol. 2009, 43, 1612-1617. [CrossRef]

45. Li, B.; Wang, X.; Qi, X.; Huang, L.; Ye, Z. Identification of rice cultivars with low brown rice mixed cadmium and lead contents and their interactions with the micronutrients iron, zinc, nickel and manganese. J. Environ. Sci. China 2012, 24, 1790-1798. [CrossRef]

46. Wang, J.; Gong, D.; Yang, J.; Zhu, J.; Fan, F.; Li, W.; Wang, F.; Zhong, W. Relationship between rice blast resistance genotypes and neck blast resistance of Japonica rice in Jiangsu province. Jiangsu J. Agr. Sci. 2016, 32, 250-256.

47. Schat, H.; Llugany, M.; Vooijs, R.; Hartley-Whitaker, J.; Bleeker, P.M. The role of phytochelatins in constitutive and adaptive heavy metal tolerances in hyperaccumulator and non-hyperaccumulator metallophytes. J. Exp. Bot. 2002, 53, 2381-2392. [CrossRef]

48. Mishra, S.; Mattusch, J.; Wennrich, R. Accumulation and transformation of inorganic and organic arsenic in rice and role of thiol-complexation to restrict their translocation to shoot. Sci. Rep. UK 2017, 7, 40522. [CrossRef]

49. Seregin, I.V.; Kozhevnikova, A.D. Physiological role of nickel and its toxic effects on higher plants. Russ. J. Plant Physiol. 2006, 53, 257-277. [CrossRef]

50. Ma, J.F.; Yamaji, N.; Mitani, N.; Tamai, K.; Konishi, S.; Fujiwara, T.; Katsuhara, M.; Yano, M. An efflux transporter of silicon in rice. Nature 2007, 448, 209. [CrossRef]

51. Meharg, C.; Meharg, A.A. Silicon, the silver bullet for mitigating biotic and abiotic stress, and improving grain quality, in rice? Environ. Exp. Bot. 2015, 120, 8-17. [CrossRef]

52. Nwugo, C.C.; Huerta, A.J. The effect of silicon on the leaf proteome of rice (Oryza sativa L.) plants under cadmium-stress. J. Proteome Res. 2010, 10, 518-528. [CrossRef] 
53. Khaliq, A.; Ali, S.; Hameed, A.; Farooq, M.A.; Farid, M.; Shakoor, M.B.; Mahmood, K.; Ishaque, W.; Rizwan, M. Silicon alleviates nickel toxicity in cotton seedlings through enhancing growth, photosynthesis, and suppressing Ni uptake and oxidative stress. Arch. Agron. Soil Sci. 2016, 62, 633-647. [CrossRef]

54. Liu, H.; Zhang, J.; Christie, P.; Zhang, F. Influence of iron plaque on uptake and accumulation of Cd by rice (Oryza sativa L.) seedlings grown in soil. Sci. Total Environ. 2008, 394, 361-368. [CrossRef]

55. Llamas, A.; Ullrich, C.I.; Sanz, A. $\mathrm{Ni}^{2+}$ toxicity in rice: Effect on membrane functionality and plant water content. Plant Physiol. Biochem. 2008, 46, 905-910. [CrossRef]

56. Rubio, M.I.; Escrig, I.; Martínez-Cortina, C.; López-Benet, F.J.; Sanz, A. Cadmium and nickel accumulation in rice plants. Effects on mineral nutrition and possible interactions of abscisic and gibberellic acids. Plant Growth Regul. 1994, 14, 151-157. [CrossRef]

57. Nie, J.; Pan, Y.; Shi, J.; Guo, Y.; Yan, Z.; Duan, X.; Xu, M. A comparative study on the uptake and toxicity of nickel added in the form of different salts to maize seedlings. Int. J. Environ. Res. Public Health 2015, 12, 15075-15087. [CrossRef]

58. Duan, G.; Shao, G.; Tang, Z.; Chen, H.; Wang, B.; Tang, Z.; Yang, Y.; Liu, Y.; Zhao, F.J. Genotypic and environmental variations in grain cadmium and arsenic concentrations among a panel of high yielding rice cultivars. Rice 2017, 10, 9. [CrossRef]

59. Zhao, F.J.; McGrath, S.P.; Meharg, A.A. Arsenic as a food chain contaminant: Mechanisms of plant uptake and metabolism and mitigation strategies. Annu. Rev. Plant Biol. 2010, 61, 535-559. [CrossRef]

60. Crush, J.R.; Ouyang, L.; Cousins, G.R. Variation in cadmium concentrations in shoots of chicory (Cichorium intybus L.). New Zealand J. Agric. Res. 2018, 62, 1-9. [CrossRef]

(C) 2019 by the authors. Licensee MDPI, Basel, Switzerland. This article is an open access article distributed under the terms and conditions of the Creative Commons Attribution (CC BY) license (http://creativecommons.org/licenses/by/4.0/). 